\title{
Drying of Electrohydrodynamic (Ehd) on Potato Slices (Solanum Tuberosum) with Electrode Distance Variation
}

\author{
Sumariyah ${ }^{1,2^{*}} \quad$ Sulistiyani Hayu Pratiwi ${ }^{1,2} \quad$ Muhammad Nur ${ }^{1,2}$ \\ 1.Departemen Fisika Universitas Diponegoro, Jl. Prof. Soedarto SH Tembalang Semarang \\ 2.Central for Plasma Research, Jl. Profesor H. Soedarto, SH FSM UNDIP, City, Tembalang, Kota \\ Semarang, Jawa Tengah 50275
}

\begin{abstract}
This research is about the use of electrohydrodynamics (EHD) on potato slices. The purpose of this study was to circumvent potato slices by comparing the results of variations in distance between the two electrodes. EHD generation is carried out using two types of electrode geometries, namely the needle electrode and the concentric ring electrode. Needle electrodes as cathodes and field electrodes or concentric rings as anode electrodes. The two electrodes are $10 \times 10$ pieces each. Drying the potato slices is carried out by placing it in a sample location parallel to the concentric ring electrode. Drying with EHD in atmospheric conditions will produce a current when given the added voltage measured on an digital multimeter. Electrode distance variations are $4 \mathrm{~mm}, 6 \mathrm{~mm}, 8 \mathrm{~mm}, 10 \mathrm{~mm}$ and $12 \mathrm{~mm}$. After drying, drying rate, shrinkage, moisture content was measured which showed a decrease with increasing distance between electrodes, while energy efficiency increased with increasing distance between electrodes. The greater the distance between the electrodes for drying the potato slices, the smaller the shrinkage and water content decreases in the sample slices.
\end{abstract}

Keywords: drying, electrohydrodynamics, electrodes, potatoes

DOI: $10.7176 / \mathrm{JNSR} / 9-24-04$

Publication date: December $31^{\text {st }} 2019$

\section{Introduction}

The food industry sector is one of the industrial sectors which has enormous potential for Indonesia's economic progress [1]. The food industry is a very important requirement, especially in agriculture [2]. One of the agricultural commodities is potatoes (Solanum Tuberosum), potato plants are tuber plants which are included in the plant family Solanaceae [3].

Before being consumed, the potatoes must be cooked first like baked, fried or dried [4]. The method of cooking potatoes which is of much concern is drying [5]. Various methods of drying potatoes have been carried out by farmers and researchers, in general potato, farmers do drying with conventional methods by utilizing sunlight heat [6]. Another method is to use ohmic heating to save $88 \%$ more than conventional methods, but this method requires considerable time [7]. Potato drying can also use the irradiation method using Co-60 sources [8].

The development of research and technology for drying experiences development and progress, which aims to improve quality and reduce energy consumption, namely using electrohydrodynamics (EHD) requires a short time for the drying process and reduces the acceleration of oxidation [9]. EHD drying is a technique for increasing heat transfer which refers to the relationship of high voltage current fields and fluid fields with low power consumption [10]. EHD has been used for drying such as; blueberries [11], wolfberry fruits from China [12], Vietnamese agricultural products [13], and spices [14,15]. EHD drying has many advantages: low power, no generator, requires moving parts, free from mechanical and acoustic vibration noise, and turns off microbes [15].

\section{Method}

Potatoes (Solanum Tuberosum) as samples are peeled and cut into slices that have a thickness of $2 \mathrm{~mm}$, a diameter of $30 \mathrm{~mm}$ and humidity of potatoes $46.6 \%$.

EHD drying uses a concentrated multi-ring pin electrode configuration with $10 \times 10$ pieces each. Consisting of an electrode pin as a cathode has a pointed end diameter of $0.026 \mathrm{~mm}$. The concentric multi-ring electrode as an anode consists of 3 concentric ring electrodes which have the same width and thickness of $2 \mathrm{~mm}$ and $8 \mathrm{~mm}, 16$ $\mathrm{mm}$ and $24 \mathrm{~mm}$ respectively. Drying of EHD on potato slices is done by varying the distance between the two electrodes namely, 4, 6, 8, 10,12 mm with a drying time of 30 minutes at $12 \mathrm{kV}$ DC (Direct Current) input voltage.

Voltage measurement is given to the system via a high voltage probe voltage divider (SEW high voltage probe P20 P28) and the voltage installed can be measured using a digital voltmeter (CD772 Sanwa Made in Tokyo, Japan). In EHD drying, one of the radiation from the release is ionic wind will flow from the electrode pin to the multi-ring concentrate electrode which will dry the potato slices which are located parallel to the multi-ring concentric electrode at a distance of $2 \mathrm{~mm}$ from the electrode center. The series of experiments in this study are shown in Figure 1. 


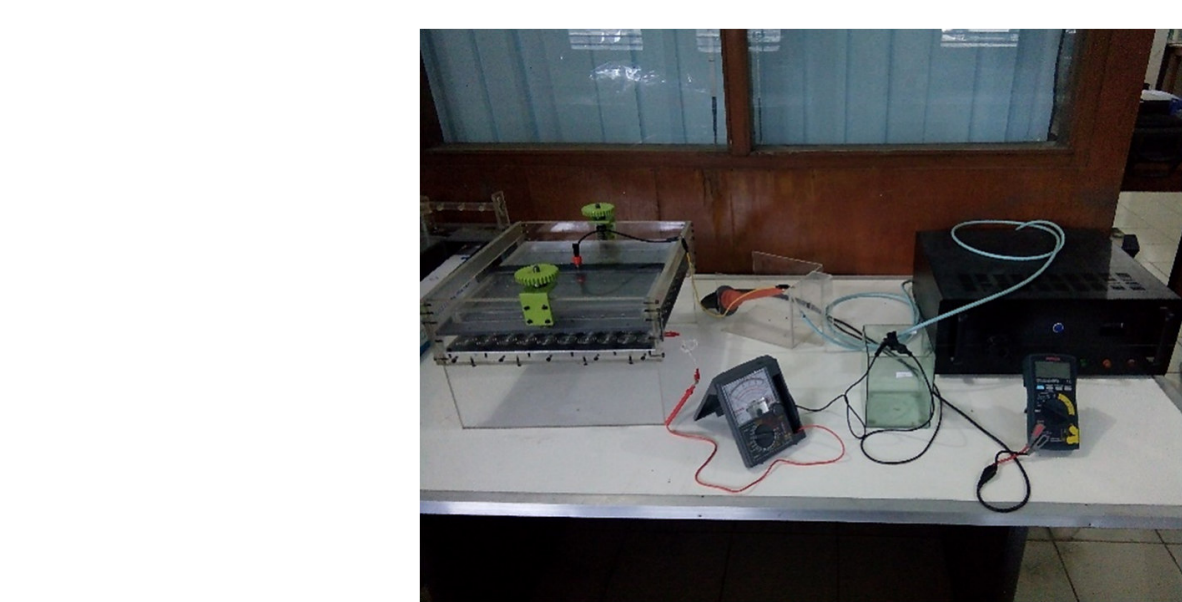

Figure 1. Scheme of research equipment series

\subsection{Drying Rate}

The measurement of the mass of potato slices was measured before and after drying for 30 minutes. The drying rate (DR) is calculated using Eq. (1) and expressed as $\mathrm{db} /$ minute.

$$
D R=\frac{\Delta m}{\Delta t}
$$

Where, $\Delta m$ is the difference in mass after and before drying $(d b), \Delta t$ is the difference in time after and before drying (minutes) [16].

\subsection{Shrinkage}

Depreciation on potato slices is affected by the condition of the initial moisture content in the sample (100\%) at each mass difference in the sample slices dried. Depreciation can be calculated using equation (2) and expressed as $(\%)$.

$$
S R=\frac{\Delta m}{m_{0}} \times 100 \%
$$

Where, $\Delta m$ is the difference in mass after and before drying $(d b), m_{0}$ is the mass before drying $(d b)$ [17].

\subsection{Moisture Content}

The water content in the potato slices is different after drying EHD, with an initial humidity of $46.6 \%$. The moisture content of the sample slices can be calculated using equation (3) and expressed as $(\% \mathrm{db})$.

$$
M C=\frac{\Delta m}{m_{0}} \times 46,6 \%
$$

Where, $\Delta m$ is the mass difference after and before drying $(d b), m_{0}$ is the mass before drying $(d b)[18]$.

\subsection{Energy Effeciency}

Energy efficiency is determined from the electric power supplied $(\mathrm{kW})$ and the drying rate $(\mathrm{kg} / \mathrm{s})$ on potato slices which can be calculated in equation (4) as $(\mathrm{kJ} / \mathrm{gr})$.

$$
\eta=\frac{V I}{\Delta m} \times \Delta t
$$

Where, $\Delta m$ is the mass difference after and before drying $(d b), \Delta t$ is the time difference after and before drying (minutes), $V$ is the input voltage $(k V)$,and $\mathrm{I}$ is the current output $(m A)[19]$.

\section{Result and Discussion}

EHD flow is generated by a strong electric field and its direction follows an electric field line which results in corona release due to the ionized gas process [20]. The ionization process at the two electrodes lasting 30 minutes at $12 \mathrm{kV}$ produces an increase in the electric field, heat transfer [21] and ion flow [22]. Thus, when drying on the potato slices, an EHD-induced mass transfer takes place [23] and an increase in the electric field [24] results in the evaporation of the mass of water in the potato slices. After drying EHD on the potato slices, the measurements are obtained as follows;

\subsection{Drying Rate}

Drying EHD on potato slices with a DC voltage of $12 \mathrm{kV}$ and variations in the distance between the two electrodes $(4 \mathrm{~mm}, 6 \mathrm{~mm}, 8 \mathrm{~mm}, 10 \mathrm{~mm}$ and $12 \mathrm{~mm}$ ) for 30 minutes resulted in a significant difference in the drying rate shown in figure 2 . 


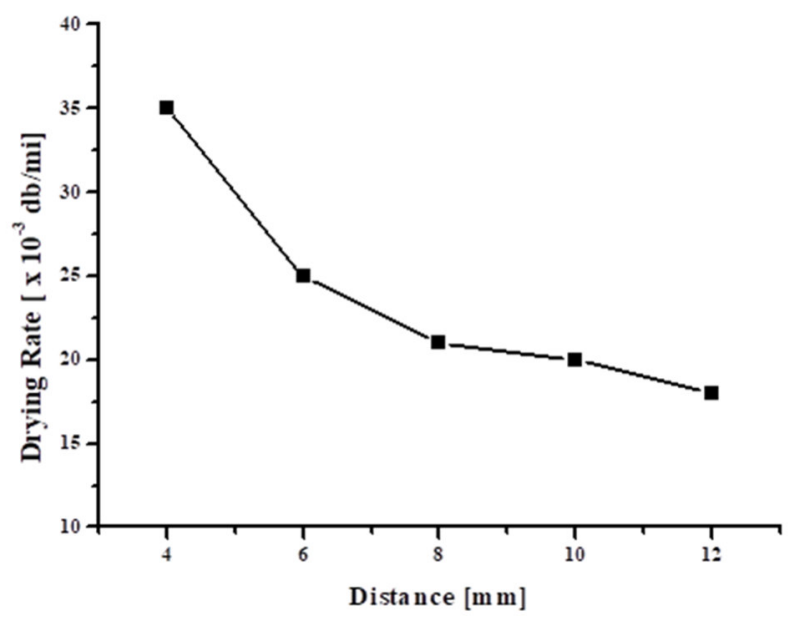

Figure 2. Graph the drying rate on the potatos (Solanum tuberosum)

In Figure 2. Value the highest drying rate is at a distance of $4 \mathrm{~mm}$ by $35 \times 10-3 \mathrm{db} / \mathrm{min}$, because of the largest electric field and ion flow. The value of the drying rate at each distance variation is different due to differences in the electric field and the flow of ions produced during EHD drying takes place. If the distance between the electrodes is small, the ionization process will be faster and the ion flow will be faster to evaporate the mass of water on the potato slices. Conversely, the distance between the two electrodes increases so that the ionization process will be longer because the electric field extends and the evaporation process of the water mass slows down. The drying rate is also influenced by the time and distance between the electrodes.

\subsection{Shrinkage and Moisture Content}

Graph the shrinkage and Moisture Content on the potatos (Solanum tuberosum) with a variations in the distance between the two electrodes for 30 minutes resulted in figure 3 .

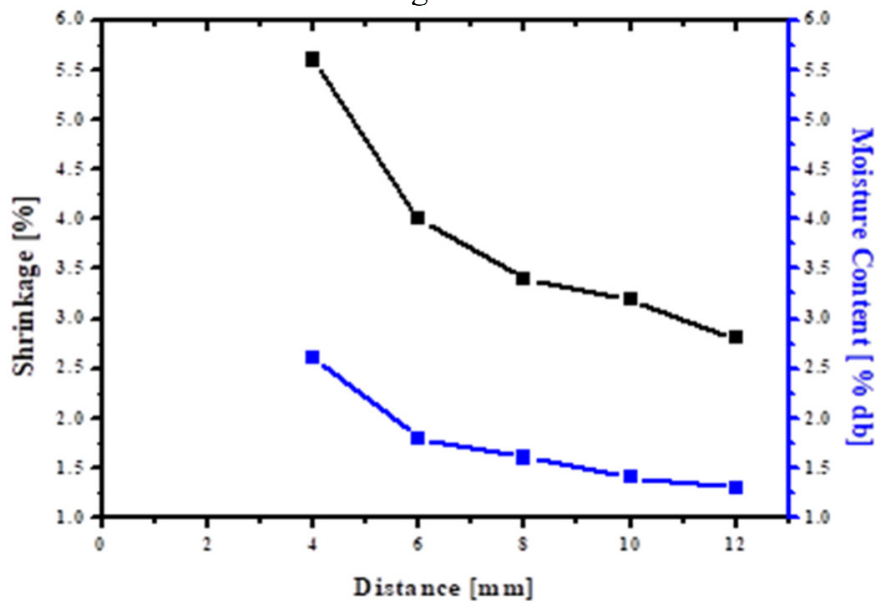

Figure 3. Graph the shrinkage and Moisture Content on the potatos (Solanum tuberosum)

The dried potato slices experience evaporation of water masses and mass transfer during drying. When the mass of water decreases on the potato slices, there is a difference in the water pressure inside and outside the potato slices which results in shrinkage which is indicated by the mass reduction of potato slices shown in Figure 3. of line black The highest shrinkage value at $4 \mathrm{~mm}$ electrode distance is $5.6 \%$ and most low at a distance of $12 \mathrm{~mm}$ by $2.8 \%$. This indicates that the depreciation value is influenced by the distance between electrodes, if the greater the distance, the smaller the shrinkage value.

In the initial condition before drying the humidity of the potatoes by $46.6 \%$ and the initial mass of 18.95 grams. After the potato slices are dried, the mass and moisture content will change every variation between the electrodes for 30 minutes. The water content obtained decreases with increasing electrode distance due to differences in an electric field, heat transfer and ion flow resulting from each variation of the electrode distance shown in figure 4 of line blue.

\subsection{Energy Effeciency}

Graph Energy Effeciency on the potatos (Solanum tuberosum) resulted in figure 4. 


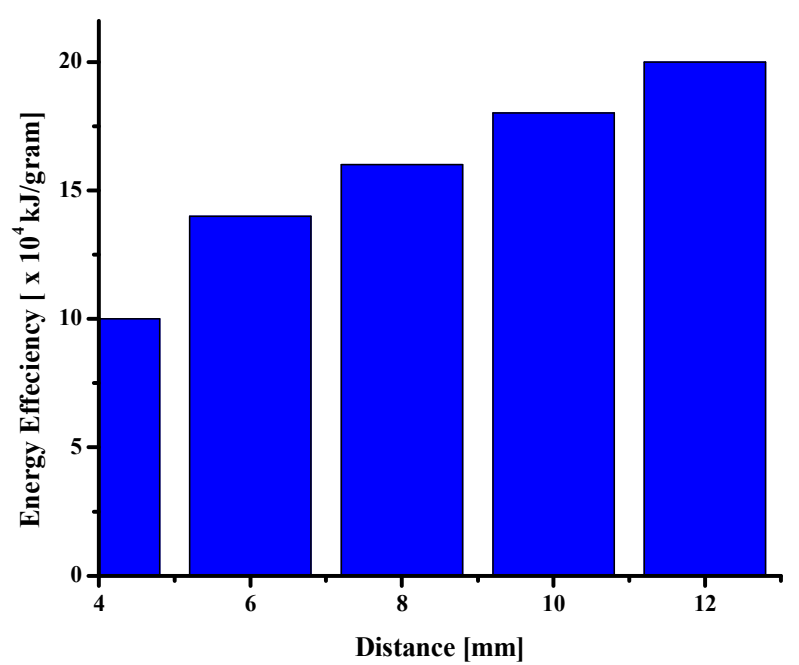

Figure 4. Graph the energy effeciency on the potatos (Solanum tuberosum)

Figure 4. shows the value of high energy efficiency at a distance of $12 \mathrm{~mm}$ by $20 \mathrm{x} 104 \mathrm{~kJ} / \mathrm{gr}$ and low at a distance of $4 \mathrm{~mm}$ by $10 \times 104 \mathrm{~kJ} / \mathrm{gr}$. Thus, the value of energy efficiency is inversely proportional to the value of the level of drying, shrinkage and moisture content. This is affected by the mass difference in the potato slices, if the mass of the potato slices is small then the high energy efficiency value is in accordance with equation (4).

\section{Conclusion}

EHD drying was utilized to potatoes slice in the voltage $12 \mathrm{kV}$ and distance of $4 \mathrm{~mm}$. Value the highest drying rate is at a distance of $4 \mathrm{~mm}$ by $35 \times 10-3 \mathrm{db} / \mathrm{min}$, value the lowerst of shrinkage by $5.6 \%$ and the velue highest of energy efficiency at a distance of $12 \mathrm{~mm}$ by $20 \mathrm{x} 104 \mathrm{~kJ} / \mathrm{gr}$. The drying rate and shrinkage decreases with increasing distance between electrodes. While the energy efficiency increases with increasing distance between the electrodes.

\section{Acknowledgements}

Special to thanks go to Center For Plasma Research (CPR) of Sains and Mathematic, Diponegoro University, for providing us with equipment and facilities and financial support to publish paper.

\section{References}

[1] Arsyad, Lincolin, and Stephanus Eri Kusuma, (2014), Industrial Economics Structure, Behavior and Performance Approach, Yogyakarta: UPP STIM YKPN.

[2] Kadek Ayu Novita Prahastha Dewi dan Eko Budi Santoso, (2014), Leading Commodity Development in Food Crops Agriculture Sector in Karangasem Regency Through Agribusiness Approach, Journal of Engineering, Pomits Vol. 3, No. 2, (2014) ISSN: 2337-3539 (2301-9271 Print)

[3] Singh, J., and Kaur L., (2016), Advances in potato chemistry and technology (2nded.). Elsevier

[4] Decker, E.A., \& Ferruzzi, M.G., (2013), Innovations in food chemistry and processing to enhance the nutrient profile of the white potato in all forms. Adv.Nutr. 4, 345S-35 0S

[4] Cátia Douradoa, Carlos Pintoa, et.al, (2019), Innovative non thermal technologies affecting potato tuber and fried potato quality, Trends in Food Science \& Technology 88, 274-289

[5] Tai-HuaMu, MiaoZhang, et.al.,(2019), Chapter 10 - Sweet potato staple food, Chemistry, Processing and Nutrition, Pages 273-302

[6] Farah naky, et.al.,(2018), Effec to fohmic and microwave cooking on some bioactive compound sofkohlrabi, turnip, potato, and radish, J. Food Meas. Charact.12, 2561-2569

[7] Soares, I. G. M., Silva, et.al.,(2016), Physico-chemical and sensory evaluation of potato (Solanum tuberosumL.) after irradiation, An. Acad. Bras. Ciênc.88,941-950

[8] Bußler, S., Ehlbeck, J., \& Schlüter, O.K.,(2017), Pre-drying treatment of plant related tissues using plasma processed air : Impac to nenzyme activity and quality attributes of cut apple and potato, Innovative Food Science \& Emerging Technologies, 40,78-86

[9] Hanafizadeh, P., Gharahasanlo, M., Ahmadi, S., Zeraati, S., Akhavan-Behabadi, M.A.,(2016), Numerical investigation of EHD effects on heat transfer enhancement and flow pattern of R134a two-phase flow, Journal of Electrostatics 82, 63-71

[10] Yougui Chen, and Alex MartynenkO,(2018), Combination of hydrothermodynamic (HTD) processing and different drying methods for natural blueberry leather, LWT, Volume 87, Pages 470-477 
[11] Maosheng Yang and Changjiang Ding,(2016), Electrohydrodynamic (EHD) drying of the Chinese wolfberry fruits, Springer Plus 5:909, pages 2-20

[12] Vu, Anh Tuan, Do, Thi Tam, et.al., (2014), Application of EHD-enhanced drying technology: a sustainable approach for Vietnam's agricultural product processing in the future, J. Viet. Env. 2014, Vol. 6, No. 3, pp. 256-263

[13] Sumariyah, Ainie Khuriati, Enny Fachriyah,(2018), Electrohydrodynamic (edh) drying of ginger slices (zingiber officinale), IOP Conf. Series: Journal of Physics: Conf. Series 1025012015

[14] Sumariyaha, Ainie Khuriati, Enny Fachriyah, 2018, Ion wind generation and its application to drying of wild Ginger slices (Curcuma Xanthorhiza), IOP Conf. Series: Journal of Physics: Conf. Series 1025012016

[15] Dinani, S.T., Havet, M., 2015, Effect of voltage and air flow velocity of combined convective electrohydrodynamic drying system on the physical properties of mushroom slices, Industrial Crops and Products 70 417-426

[16] Małgorzata Nowacka ,Artur Wiktor, et al. , (2012), Drying of ultrasound pretreated apple and its selected physical properties, Journal of Food Engineering, Volume 113, Issue 3, Pages 427-433

[17] A.A. El-Sebaii, S.M. Shalaby,(2013), Experimental investigation of an indirect-mode forced convection solar dryer for drying thymus and mint, Energy Convers Manage, 74 (2013), pp. 109-116

[18] Alex Martynenko, A., Zheng, W.,(2016), Electrohydrodynamic drying of apple slices: Energy and quality aspects, Journal of Food Engineering 168 215-222

[19] Sumariyah, Kusminarto, et. al.,(2016), Study of EHD flow generator's efficiencies utilizing pin to single ring and multi-concentric rings electrodes, Journal of Physics: Conference Series 776012100

[20] Alex Martynenko, Tadeusz Kudra,(2016), Electrically-induced transport phenomena in EHD dryinge A review, Trends in Food Science \& Technology, Volume 54, August 2016, Pages 63-73

[21] Sumariyah, Kusminarto, AriefHermantoA., danNuswantoro P,(2015), Velocity Measurement of EHD Flow Produced by Pin-Multi Concentric Ring electrodes Generator, Applied Mechanics and Materials Vol 771 pp 227-231

[22] Alex Martynenko, Tess Astatkie, et.al.,(2017), Driving forces for mass transfer inelectrohydrodynamic (EHD) drying, Innovative Food Science \& Emerging Technologies Volume 43, Pages 18-25

[23] Pour, M. S., \& Esmaeilzadeh, E., (2011), Experimental investigation of convective heattransfer enhancement from 3D-shape heat sources by EHD actuator in duct flow. Experimental Thermal and Fluid Science, 35 , $1383 \mathrm{e} 1$ 